Available online at GSC Online Press Directory

GSC Biological and Pharmaceutical Sciences

e-ISSN: 2581-3250, CODEN (USA): GBPSC2

Journal homepage: https://www.gsconlinepress.com/journals/gscbps

(RESEARCH ARTICLE)

\title{
Triazole fungicides induce hepatic lesions and metabolic disorders in rats
}

\author{
Jalal Mariam, Nchioua Zakariya, Chouham Said and Ez-Zaher Latifa *
}

Ibn Zohr University, Faculty of Science, Laboratory of Cell Biology and Molecular Genetics, Agadir, Morocco.

Publication history: Received on 07 January 2020; revised on 15 January 2020; accepted on 20 January 2020

Article DOI: https://doi.org/10.30574/gscbps.2020.10.2.0002

\begin{abstract}
Pesticides are chemicals used in the treatment of agricultural products to increase production to meet growing consumer's demand. Several studies have shown the toxic effects of these substances in humans as endocrine disrupters. The objective of our study is to highlight the toxic effects of hexaconazole in rats; a fungicide widely used in agriculture in Morocco. 16 rats received $100 \mathrm{mg} / \mathrm{kg} /$ day of hexaconazole orally via diet for 12 weeks. Biochemical analyses of the blood of treated animals showed a significant increase in creatinine, bilirubin, ASAT, ALAT and LDH levels, which would indicate toxicity in different organs. Also, a histological study of the liver was carried out. Microscopic observations showed several liver damages, such as centrilobular vein congestion, necrosis, immune cells infiltration, cholestasis, microvesicular and macrovesicular steatosis. These biochemical and histological results show that exposure to hexaconazole can cause liver and kidney damage. This pesticide would present an actual or potential danger to the consumer's health.
\end{abstract}

Keywords: Triazole; Hexaconazole; Toxicity; Hepatic lesions; Metabolic disorders; Rat

\section{Introduction}

Humans can be exposed to pesticides through several routes, but traces present in food are a worrying pathway of contamination [1]. According to the Food and Agriculture Organization of the United Nations (FA0), global pesticide consumption exceeded 4 million tonnes in 2016 [2].

Pesticides have been implicated in the development of several pathologies such as endocrine, neurological and immune system disorders. They are responsible for about one million acute poisonings per year with a mortality rate of 0.4 to 1.9\% according to statistics by the World Health Organization (WHO) [3].

Triazoles are a family of fungicides discovered in 1960. It is one of the most ten categories of pesticides used today [4]. Triazoles inhibit the synthesis of fungal ergosterols. Several studies have shown that exposure to these triazoles induces liver toxicity and carcinogenicity [5,6]. Lately, they have been considered as potential endocrine disrupters and may interfere with the biosynthesis of steroidal hormones in mammals [7].

Hexaconazole is a systemic fungicide that shares the same properties as other triazoles, interfering with steroid synthesis. It inhibits the activity of cytochrome P51 (CYP51) that plays a role in the conversion of lanosterol to ergosterol in fungi and yeasts [8].

This substance is metabolized in the liver by the cytochrome P450 enzymes [8]. Hexaconzole is then broken down into metabolites that are eliminated by the kidneys or accumulated in the body's tissues. Hexaconazole has been detected in kidneys, liver and blood tissue [9].

\footnotetext{
${ }^{*}$ Corresponding author

E-mail address: I.ezzaher@uiz.ac.ma
} 
The objective of our work is to highlight the toxic effects of hexaconazole in rats, through biochemical analyses and a histological study of the liver tissue.

\section{Material and methods}

\subsection{Treatment}

24 Albino Wistar rats of both sexes were treated orally with hexaconazole via diet, daily at a set time, for 12 weeks. The rats had free access to water and a standard diet (about $5 \mathrm{~g}$ of food per $100 \mathrm{~g}$ of body weight). The

Animals were separated into a control group consisting of 08 rats, and a treated group consisting of 16 rats in individual cages receiving the same diet mixed with $100 \mathrm{mg} / \mathrm{kg} /$ day of hexaconazole (Hexa® $5 \%$ ).

\subsection{Blood collection}

Blood was collected weekly from the tail vein according to the protocol described by Graham Lee [10].

\subsection{Biochemical analyses}

Different metabolic parameters were quantified and compared in control and treated rats before and during hexaconazole treatment.

Creatinine: a metabolite of creatine. An increase in plasma creatinine levels would indicate nephrotoxicity.

ASAT (Aspartate Aminotransferase): a transaminase found in large quantities in muscles, liver, kidneys and brain. An attack on these organs leads to its release into the bloodstream.

ALAT (Alanine Aminotransferase): its increased release into the bloodstream indicates hepatotoxicity.

Bilirubin: yellow pigment, produced by the degradation of hemoglobin. The liver ensures its degradation. Its increase in blood reflects liver failure or increased hemoglobin degradation.

LDH (Lactate deshydrogenases): enzymes that catalyze the conversion of pyruvate to lactate. They are used as markers of tissue damage (hemolysis, cancer cells renewal, etc.).

Blood count (data not shown).

\subsection{Histological study}

At the end of the treatment period, the control and treated rats were sacrificed. The liver was rapidly removed, washed with a solution of sodium chloride $(0.9 \% \mathrm{NaCl})$ and preserved in a $4 \%$ paraformaldehyde, then subjected to a histological preparation comprising different steps: fixation, dehydration, paraffin inclusion, cutting and staining [11]. Two staining methods were used in this study:

- Hematoxyline-Eosin (HE) staining.

- Masson Trichrome staining: This method was performed using the Masson Diapath® trichrome kit reagents to show the distribution of collagen fibers in the hepatic tissues collected $[12,13]$.

\subsection{Statistical analysis}

The statistical analysis was performed using Graph Pad Prism 8 for MacOs system.

Comparisons were made by the Student test.

The results are presented as mean \pm standard error and considered statistically significant at $\mathrm{p}<0.05$. 


\section{Results and discussion}

\subsection{Biochemical analyses}

\subsubsection{Effect of hexaconazole on transaminases}

Analyses showed a highly significant increase $(\mathrm{P}<0.0001)$ in ASAT levels in hexaconazole treated rats (243.73 $\pm 54.71 \mathrm{U} / \mathrm{L})$ compared to control rats $(151.17 \pm 6.05 \mathrm{U} / \mathrm{L})$ (Figure $1 \mathrm{~A})$.

Similarly, a very significant increase $(\mathrm{P}<0.0002)$ in ALAT levels was observed in the treated group $(107.09 \pm 62.01 \mathrm{U} / \mathrm{L})$, compared to $57 \pm 7.54 \mathrm{U} / \mathrm{L}$ in control rats $(\mathrm{P}<0.0002)$ (Figure $1 \mathrm{~B})$.

Results of our study in rats confirm those described by INERIS, 2011 [14]. It has been shown that the administration of hexaconazole at a low dose $(0.5 \mathrm{mg} / \mathrm{kg})$ for 2 years caused liver damage in rats (Rattus norvegicus).
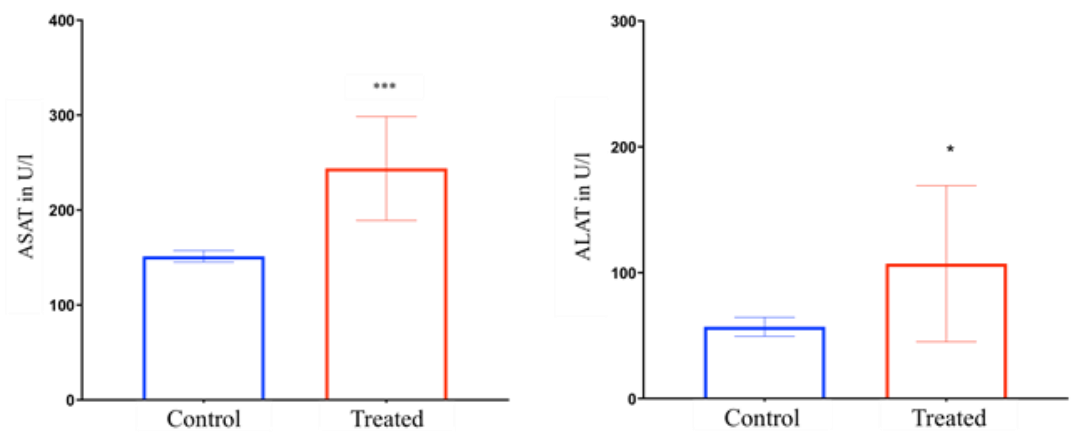

Figure 1 Transaminases analysis in control and treated rats.

(A) ASAT analysis and (B) ALAT analysis in control rats and treated rats. Each value is an average \pm SEM of the ASAT and ALAT values in the control and treated rats, and represents a significance at $\mathrm{P}<0.05$.

\subsubsection{Effect of hexaconazole on bilirubin}

Hexaconzole treatment caused an increase in bilirubin levels in treated rats $(1.27 \pm 0.45 \mathrm{mg} / \mathrm{L})$ compared to control rats $(0.58 \pm 0.12 \mathrm{mg} / \mathrm{L})$. This difference is significant at $\mathrm{P}<0.0001$ (Figure 2 ).

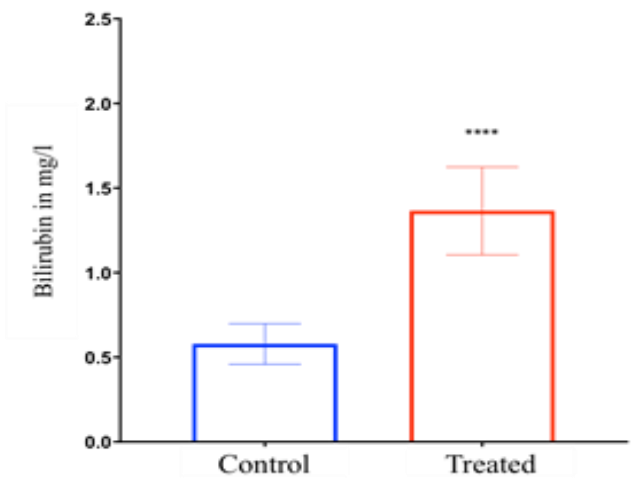

Figure 2 Bilirubin analysis in control and treated rats.

Each value is an average \pm SEM of the Bilirubin values in control and treated rats, and represents significance at $\mathrm{P}<0.05$.

Bilirubin is a degradation product of hemoglobin. Hexaconazole administration caused an increase in bilirubin levels in treated rats. However, since the number of red blood cells was not affected (data not shown), this suggests that there is a deficit in liver function. The liver becomes unable to maintain bilirubin normal levels [15]. In addition, Amacher (1998) [16] have shown that an increase in bilirubin levels indicates liver toxicity. 


\subsubsection{Effect of hexaconazole on LDH levels}

$\mathrm{LDH}$ level attains a value of $2151.8 \pm 284.45 \mathrm{U} / \mathrm{L}$ in treated rats, while it is only $165.6 \pm 57.22 \mathrm{U} / \mathrm{L}$ in control rats. A very significant difference is found at $\mathrm{P}<0.05(\mathrm{P}<0.0001)$ (Figure 3).

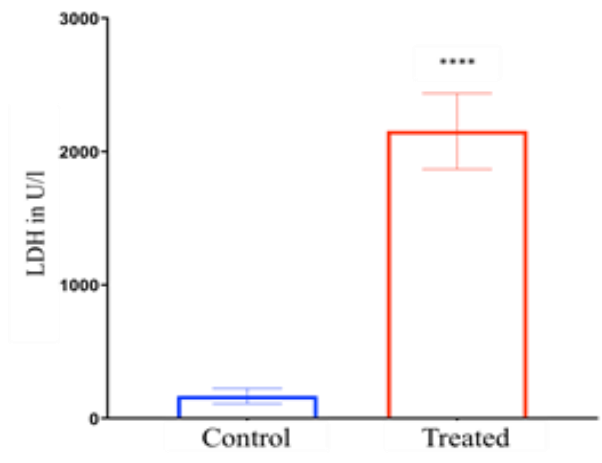

Figure $3 \mathrm{LDH}$ analysis in control and treated rats.

Each value is an average \pm SEM of the LDH values in control and treated rats, and represents a significance at $\mathrm{P}<0.05$.

LDH is a glycolytic enzyme found in most animal tissues, specifically muscles, heart, liver, kidneys, brain, lung and red blood cells [17]. In our study, rats treated with hexaconazole showed 13 times higher serum LDH levels than control rats. In addition, an increase in LDH levels has been observed with other triazole fungicides: myclobutanil, propiconazole, and triadimefon [18].

\subsubsection{Effect of hexaconazole on creatinine}

Biochemical analysis of creatinine shows a significant difference at $\mathrm{P}<0.05 \quad(\mathrm{P}<0.0001)$ between control $(5.45 \pm 0.26 \mathrm{mg} / \mathrm{L})$ and treated rats $(6.67 \pm 0.59 \mathrm{mg} / \mathrm{L})$ (Figure 4$)$. Comparable results have been reported using other triazole fungicides: myclobutanil and triadimefon. Rats of the Sprague-Dawley strain were treated for 14 days with doses ranging from 5 to $150 \mathrm{mg} / \mathrm{kg} /$ day [19].

Creatinine is a product of creatine degradation, most of which is eliminated by the kidneys. An increase in creatinine levels in the bloodstream is a good indicator of kidney's toxicity [20].

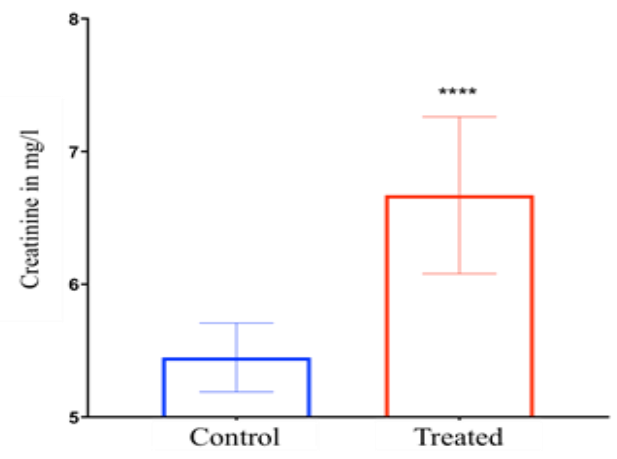

Figure 4 Creatinine analysis in control and treated rats.

Each value is an average \pm SEM of the Creatinine values in control and treated rats, and represents a significance at $\mathrm{P}<0.05$.

\subsection{Histological study}

Microscopic observation of histological sections of the liver corroborates the toxic effect of hexaconazole revealed by the results of the biochemical analysis. 
In control rats, the hepatic tissue shows a normal architecture containing centrilobular veins and hepatocytes of the usual shape, as well as some Kupffer cells in the sinusoids scattered throughout the tissues (Figure 5A and 6A).

In addition, microscopic observation of the liver in treated rats showed congestion of the centrilobular veins and sinusoids, as well as the onset of necrosis. We observed the infiltration of immune cells, and a few binucleated cells (Figure 6B). Also, we observed an accumulation of bilirubin in the hepatocytes (cholestasis) and microvesicular and macrovesicular steatosis (vacuoles loaded with fat and fat droplets) (Figure 5B and 6C).Peffer and al., (2007) [21] also observed cell proliferation, unicellular necrosis, and vacuolation of fats in the liver in mice treated with 200 ppm cyproconazole for 14 days. The same effects were also observed in liver tissue in fish (Sebastiscus marmoratus) exposed to paclobutrazol (triazole fungicide) for 50 days [22].

Several possible mechanisms have been developed to explain the appearance of these numerous liver lesions. Previous studies have suggested that hepatic nuclear receptors, in particular, the PXR receptor (pregnane X receptor) and the androstane constitutive receptor (CAR), play an important role in the metabolism of xenobiotics. In addition to regulating detoxification, PXR has been reported to promote lipogenesis and suppress fatty acid oxidation leading to the accumulation of liver lipids. On the other hand, CAR inhibits neoglucogenesis and lipid metabolism and lowers serum triglyceride levels. Thus, these two PXR and CAR receptors appear to play a central role in regulating energy metabolism, and their activation or inhibition may lead to hepatic steatosis [23]. Similarly, previous studies have shown that reactive oxygen species (ROS), produced by many pesticides, including some triazoles, are often involved in the development of oxidative damage and lesions in liver tissue [24, 25]. Some studies indicate that triazoles, in addition to inhibiting ergosterol biosynthesis, the essential component of the fungal membranes of many fungi, via CYP51 inhibition, also target mammalian and other vertebrate CYP51, which catalyzes the formation of zymosterol, a precursor to cholesterol, which can lead to changes in liver function [26].
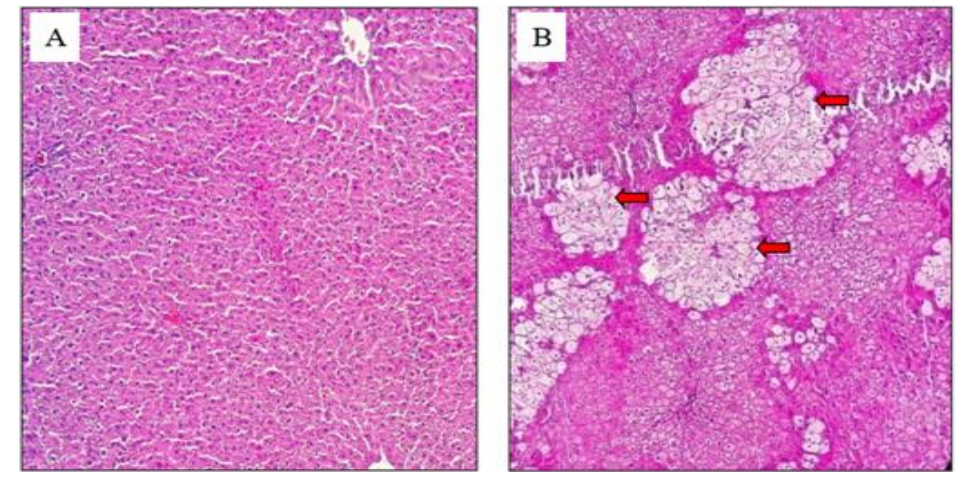

Figure 5 Histological section of the hepatic tissue. hematoxylin- eosin staining/ (X 100)

(A) Histological section of the normal liver. (B) Hepatic steatosis hexaconazole-treated rat (red arrow).
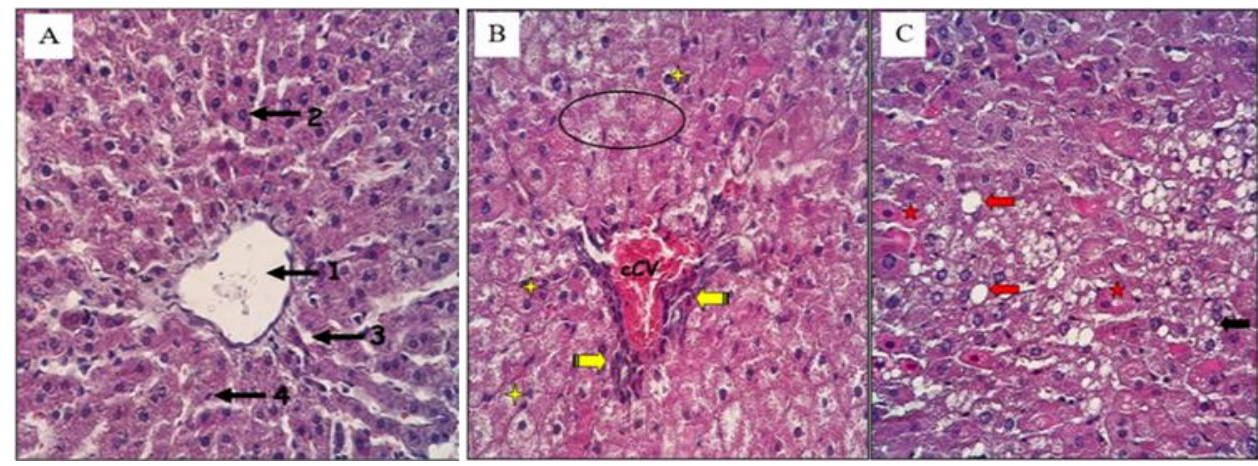

Figure 6 Histological section of the hepatic tissue of the control rat (A) and the hexaconazole treated rat (B) and (C); hematoxylin-eosin staining/ (X 400).

(A) (1): Centrilobular vein; (2): Hepatocytes; (3) Sinusoid; (4): Kupffer cells. (B) Congestion of centrilobular veins (cCV), lymphocytic infiltration (yellow arrow), necrotic cells (circle) and double nucleus cells (four-pointed star). (C) Accumulation of bilirubin in the hepatocytes (five-pointed star) and microvesicular (black arrow) and macrovesicular (red arrow) steatosis. 
Liver tissue samples from control rats stained by the Masson Trichrome method show fine collagen fibers around the centrilobular and portal veins (Figure 7A). In contrast, the hepatic tissues of treated rats show a distortion of hepatic architecture illustrated by an apparent increase in the amount of collagen fibers, indicating intense fibrosis in the portal and periportal area (Figure 7C), as well as bridge fibrosis that extends by connecting the portal space to the centrilobular veins (formation of collagen septa) (Figure 7B).

Complex molecular and cellular mechanisms are involved in the development of hepatic fibrosis. Activation and transformation of hepatic stellate cells (HSCs) into contractile myofibroblasts are considered to be the two main reasons for the development of hepatic fibrosis [27].

Receptors activated by peroxisome proliferation inducers (PPARs) belonging to the family of ligand-activated transcription factors play a key role in liver homeostasis, regulating adipogenesis and inhibiting the transformation of stellate cells into contractile myofibroblasts. The normal transcription function of PPARs helps to maintain these cells in the quiescent phase. Reduced PPAR expression will induce increased hepatic fibrosis and collagen production [28]. Sun and al., (2013) [22] showed that fungicides, which belong to the triazole family, affect liver function via multiple signaling pathways of nuclear receptors such as PPAR.
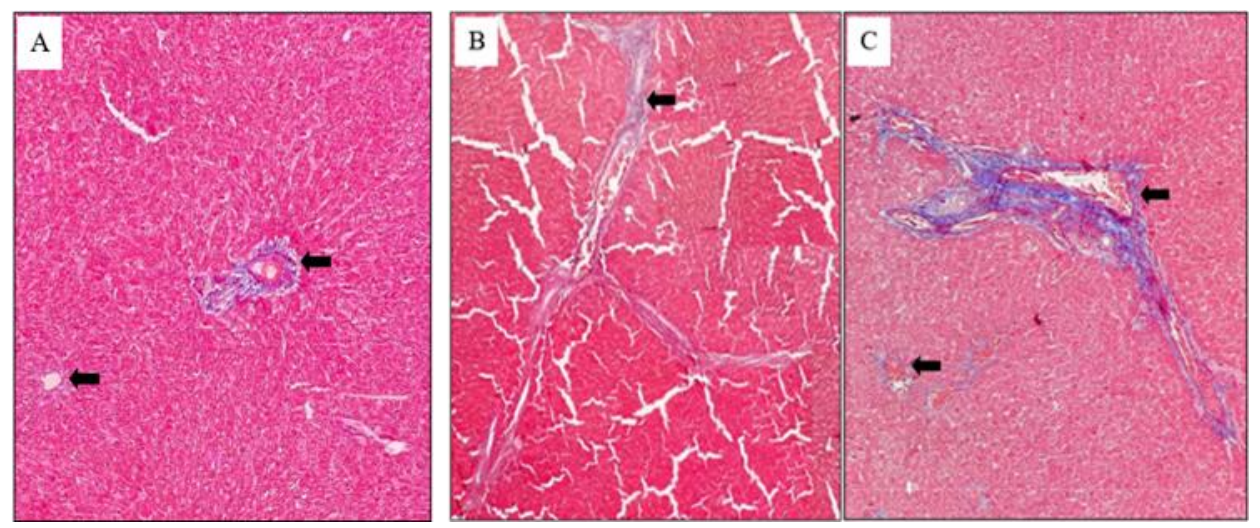

Figure 7 Histological section of hepatic tissue of control rats (A) and rats treated with hexaconazole (B) and (C) Masson Trichrome /(X 100). (Arrows: collagen fibers)

\section{Conclusion}

The results obtained in this study indicate that exposure of rats to hexaconazole at a dose of $100 \mathrm{mg} / \mathrm{kg}$ for $12 \mathrm{weeks}$ may lead to variations in the levels of certain metabolic parameters indicative of toxicity, as well as the appearance of numerous liver lesions (steatosis, cholestasis, and fibrosis), affecting liver function. These adverse effects of hexaconazole found in rats reveal the toxicity of this substance, which is widely used in the treatment of agricultural products. Chronic exposure to hexaconazole could represent a real danger to human health.

\section{Compliance with ethical standards}

\section{Acknowledgments}

We would like to thank Dr. Aghrouch .M and Dr. Aksim M.of the medical analysis laboratory and the anatomic pathology laboratory of Hassan II Hospital in Agadir for their fruitful collaboration and their contribution to the realization of this study.

\section{Disclosure of conflict of interest}

Jalal Mariam, Nchioua Zakariya, Chouham Said and Ez-Zaher Latifa declare that they have no conflict of interest.

\section{Statement of ethical approval}

The experiment was carried out at Ibn Zohr University, Faculty of Science, Laboratory of Cell Biology and Molecular Genetics, in accordance with approval by Consultative Commission on Bioethics. Ref N : AE-02/2020-0001. 


\section{References}

[1] Rather IA, Koh WY, Paek WK and Lim J. (2017). The sources of chemical contaminants in food and their health implications. Frontiers in pharmacology, 8, 830.

[2] Faostat FAO. (2016). Statistical databases. Food and Agriculture Organization of the United Nations.

[3] Garcia FP, Ascencio SYC, Oyarzun JG, Hernandez AC and Alavarado PV. (2012). Pesticides: classification, uses and toxicity. Measures of exposure and genotoxic risks. J. Res. Environ. Sci. Toxicol, 1(11), 279-293.

[4] Fenner K, Canonica S, Wackett LP and Elsner M. (2013). Evaluating pesticide degradation in the environment: blind spots and emerging opportunities. Science, 341(6147), 752-758.

[5] Hester SD, Wolf DC, Nesnow S and Thai SF. (2006).Transcriptional profiles in liver from rats treated with tumorigenic and non-tumorigenic triazole conazole fungicides: propiconazole, triadimefon and myclobutanil. Toxicologic pathology, 34(7), 879-894.

[6] Goetz AK and Dix DJ. (2009). Toxicogenomic effects common to triazole antifungals and conserved between rats and humans. Toxicology and applied pharmacology, 238(1), 80-89.

[7] Poulsen R, Luong X, Hansen M, Styrishave B and Hayes T. (2015). Tebuconazole disrupts steroidogenesis in Xenopus laevis. Aquatic Toxicology, 168, 28-37.

[8] Shen Z, Liu D, Wang P, Zhang P, Wang X and Zhou Z. (2013). Gender-related in vitro metabolism of hexaconazole and its enantiomers in rats. Chirality, 25(12), 852-857.

[9] Wang QX, Qiu J, Wang P, Jia GF, Wang P, Li JL and Zhou ZQ. (2005). Stereoselective kinetic study of hexaconazole enantiomers in the rabbit. Chirality: The Pharmacological, Biological, and Chemical Consequences of MolecularAsymmetry 17(4), 186-192.

[10] Lee G and Goosens KA. (2015). Sampling blood from the lateral tail vein of the rat. JoVE (Journal of Visualized Experiments), (99), e52766.

[11] Houlot R. (1984). Techniques d'histologie et de cytologie. Paris: Edition Maloine human disease: an overview. Methods Enzymol, 186, 1-85.

[12] Prophet EB. (1992). Laboratory methods in histotechnology. American Registry of Pathology.

[13] Bancroft JD and Gamble M. (2002). Theory and practice of histological techniques (5th ed). Churchill Livingstone. New York.

[14] Institut national de l'environnement industriel et des risques, INERIS. (2011). Hexaconazole - CAS No. 79983-71$4,1-21$.

[15] Kalakonda A and John S. (2019). Physiology, Bilirubin.

[16] Amacher DE. (1998). Serum transaminase elevations as indicators of hepatic injury following the administration of drugs. Regulatory toxicology and pharmacology, 27(2), 119-130.

[17] Berridge BR, Van Vleet JF and Herman E. (2013). Cardiac, vascular, and skeletal muscle systems. In Haschek and Rousseaux's Handbook of Toxicologic Pathology, 1567-1665.

[18] Goetz AK, Rockett JC, Ren H, Thillainadarajah I and Dix DJ. (2009). Inhibition of rat and human steroidogenesis by triazole antifungals. Systems biology in reproductive medicine, 55(5-6), 214-226.

[19] Ekman DR, Keun HC, Eads CD, Furnish CM, Murrell RN, Rockett JC and Dix DJ. (2006). Metabolomic evaluation of rat liver and testis to characterize the toxicity of triazole fungicides. Metabolomics, 2(2), 63-73.

[20] Wyss M and Kaddurah-Daouk R. (2000). Creatine and creatinine metabolism. Physiological reviews, 80(3), $1107-$ 1213.

[21] Peffer RC, Moggs JG, Pastoor T, Currie RA, Wright J, Milburn G and Rusyn I. (2007). Mouse liver effects of cyproconazole, a triazole fungicide: role of the constitutive androstane receptor. Toxicological sciences, 99(1), 315-325.

[22] Sun L, Li J, Zuo Z, Chen M and Wang C. (2013). Chronic exposure to paclobutrazol causes hepatic steatosis in male rockfish Sebastiscus marmoratus and the mechanism involved. Aquatic toxicology, 126, 148-153.

[23] Konno Y, Negishi M and Kodama S. (2008). The roles of nuclear receptors CAR and PXR in hepatic energy metabolism. Drug metabolism and pharmacokinetics, 23(1), 8-13. 
[24] Heikal TM, El-Sherbiny M, Hassan SA, Arafa A and Ghanem HZ. (2012). Antioxidant effect of selenium on hepatotoxicity induced by chlorpyrifos in male rats. Int J Pharm Sci, 4(4), 603-609.

[25] Roelofs MJ, Temming AR, Piersma AH, van den Berg M and van Duursen MB. (2014). Conazole fungicides inhibit Leydig cell testosterone secretion and androgen receptor activation in vitro. Toxicology reports, 1, 271-283.

[26] Strushkevich N, Usanov SA and Park HW. (2010). Structural basis of human CYP51 inhibition by antifungal azoles. Journal of molecular biology, 397(4), 1067-1078.

[27] Mann DA and Smart DE. (2002). Transcriptional regulation of hepatic stellate cell activation. Gut, 50(6), 891-896.

[28] Yang L, Chan CC, Kwon OS, Liu S, McGhee J, Stimpson SA and Rockey DC. (2006). Regulation of peroxisome proliferator-activated receptor- $\gamma$ in liver fibrosis. American Journal of Physiology-Gastrointestinal and Liver Physiology, 291(5), G902-G911.

\section{How to cite this article}

Jalal M, Nchioua Z, Chouham S and Ez-Zaher L. (2020). Triazole fungicides induce hepatic lesions and metabolic disorders in rats. GSC Biological and Pharmaceutical Sciences, 10(2), 40-47. 